Abstracta Iranica

Revue bibliographique pour le domaine irano-aryen

Volume 34-35-36 | 2017

Comptes rendus des publications de 2011-2013

\title{
Elaine Wright. The Look of the Book. Manuscript Production in Shiraz, 1303-1452
}

\section{Frantz Chaigne}

\section{(2) OpenEdition}

1 Journals

\section{Édition électronique}

URL : http://journals.openedition.org/abstractairanica/42207

DOI : 10.4000/abstractairanica.42207

ISSN : 1961-960X

Éditeur :

CNRS (UMR 7528 Mondes iraniens et indiens), Éditions de l'IFRI

Référence électronique

Frantz Chaigne, "Elaine Wright. The Look of the Book. Manuscript Production in Shiraz, 1303-1452 ", Abstracta Iranica [En ligne], Volume 34-35-36 | 2017, document 21, mis en ligne le 30 juillet 2017, consulté le 26 septembre 2020. URL : http://journals.openedition.org/abstractairanica/42207 ; DOI : https://doi.org/10.4000/abstractairanica.42207

Ce document a été généré automatiquement le 26 septembre 2020.

Tous droits réservés 


\title{
Elaine Wright. The Look of the Book. Manuscript Production in Shiraz,
} 1303-1452

\author{
Frantz Chaigne
}

\section{RÉFÉRENCE}

Elaine Wright. The Look of the Book. Manuscript Production in Shiraz, 1303-1452. Washington, Freer Gallery of Art, Smithsonian Institution, in association with University of Washington Press, 2013, 399 p., 133 ill. couleur.

1 Dans la présente publication, Elaine Wright décrypte sous diverses facettes la production manuscrite de Chiraz sur une période d'un siècle et demi, couvrant les règnes des dynasties inju'ide, muzaffaride, et timouride. Pour ce faire, l'A. s'appuie sur un corpus riche de 377 manuscrits et folios.

2 Le premier chapitre (p. 3-124) consiste en une étude extrêmement serrée de l'enluminure au sein du corpus d'étude. Wright utilise une double méthodologie : d'une part l'étude de séries, permettant de dégager des caractères de groupes réduits, d'autre part une analyse de manuscrits remarquables pris dans leur singularité, à l'instar du coran de Fars Malik Khatun. Adoptant une approche diachronique, l'A. distingue des évolutions rapides dans les programmes : cette démarche lui permet ainsi d'ériger la notion de " programme » en marqueur chronologique très précis. Les résultats de ce procédé sont magistralement illustrés dans l'étude des manuscrits inju'ides, où les caractéristiques programmatiques de deux périodes sont nettement mises en évidence. Les comparaisons avec les productions ilkhânides et jalâ'irides permettent de comprendre que le programme enluminé constitue aussi un indicateur géographique. Enfin, concernant le remplissage des structures enluminées, le travail d'Elaine Wright présente l'originalité de confronter le décor de manuscrits avec celui des métaux, et ce sur les différentes périodes abordées. Ainsi, ce chapitre démontre la pertinence d'un 
travail d'analyses fouillées et croisées pour poser des jalons chronologiques resserrés et démontrer les transferts de motifs entre supports.

Des méthodes aussi détaillées sont mises en œuvre dans les chapitres suivants, respectivement dévolus à la codicologie (p. 125-52), l'illustration (p. 153-230), la calligraphie (p. 231-254) et la reliure (p. 255-82). Précédant la conclusion et les annexes, un sixième chapitre (p. 283-92) résume les caractéristiques esthétiques, codicologiques, sociologiques et politiques des trois grandes phases que distingue Wright à travers ce siècle et demi, à savoir : les origines de la période dite " classique » (fin des années 1350 années 1360), le temps d'Iskandar Sultan (r. 1409-1414) et enfin la décennie suivant la mort d'Ibrahim Sultan (1435-1445).

\section{AUTEURS}

\section{FRANTZ CHAIGNE}

UMR 8167, chercheur associé 